\title{
Roqia Al-Azzani (TBI) Serial CT Control Analysis of Necessity and Outcome
}

\author{
Roqia al-azzani* and Ismail Alkebsi \\ Department of Neurosurgery, Althawra Modern General Hospital, Yemen
}

Submission: January 19,2018; Published: September 04, 2018

*Corresponding author: Roqia al-azzani, Department of Neurosurgery, Althawra Modern General Hospital, Yemen, Email: Roqial-azzani@ynss-ye.org

\begin{abstract}
Background: TBI is a leading cause of death and disability around the globe. The Glasgow Coma Scale (GCS) and the Glasgow Outcome Scale (GOS) are the most widely used methods of describing TBI and measure of outcome following head injury. Computed tomography (CT) has become the current standard for diagnosing intracranial pathology following head trauma The aims of this study were to identify radiological features of patients in who repeated CT imaging would be useful and to identify the outcome of head trauma, according to Glasgow Outcome Scale .In addition to make a development of a stratification protocol of patients into appropriate risk groups avoiding over or under investigation in such patients.
\end{abstract}

Method: A retrospective case series study analysis of head trauma patients presenting to the 48 Medical Model Compound Hospital between January and March 2017. All patients requiring a CT head on admission and then a repeat (control) CT at 6 hours or more were included. Their GCS was assessed twice before undergoing the control brain CT scans; once they arrived at the hospital, then followed by another assessment after 3 hours and assessed GOS on discharge.

Results: Of the total 27-control brain CTs, it was seen there were no different in 23 (85.2\%). In CTs of anther 1 (3.7\%) there was increasing in the pathology present. And in the anther $3(11.11 \%)$ there were a decrease in the pathology. Over all, all patients had clinical improvement and good outcome depending on of GCS and Glasgow Outcome Scale respectively.

Conclusion: To conclude, control brain CT scans after 6 hours or more from the event are not necessary in case the initial CT was normal or when there is no clinical deterioration Background. Traumatic Brain Injury (TBI) is defined as damage to the brain resulting from external mechanical force, such as rapid acceleration or deceleration, impact, blast waves, or penetration by a projectile and presents a major worldwide social, economic, and health problem [1]. TBI is a leading cause of death and disability around the globe [2]. In developing countries, the incidence of traumatic brain injury is increasing as traffic increases, besides Other confounding factors such as industrialization, falls and ballistic trauma [3]. The most widely used methods of describing TBI are the Glasgow Coma Scale (Figure 1). It is predictive of mortality in a general TBI population. The Glasgow Outcome Scale (Figure 2) is the most widely used and accepted measure of outcome following head injury [4-6].

Computed Tomography (CT) is the preferred radiologic test in TBI it is quick, accurate, and widely available, it has become the current standard for diagnosing intracranial pathology following head trauma. And the role of the initial brain CT scan and of unscheduled repeat brain CTs when a neurological deterioration occurs is well established. But using of routine serial head CT in patients without neurologic deterioration is not supported by the findings of Brown et al [7-10].

The aims of this study are to identify radiological features of patients in who repeated CT imaging would be useful and to Identify the outcome of head trauma, according to Glasgow Outcome Scale [11]. In addition to make a development of a stratification protocol of patients into appropriate risk groups avoiding over or under investigation in such patients.

Keywords: Roqia al-azzani; Traumatic Brain Injury; Roqia al-azzani; Traumatic brain injury; control analysis; Necessity; Outcome; Management; Patients; Anticoagulant; Telephone; Glasgow coma scale; Computed tomography; Globe; Neurosurgery; Hospital; Radiation

Abbreviations: TBI: Traumatic brain injury; GCS: Glasgow Coma Scale; GOS: Glasgow Coma Scale; CT: Computed tomography;

\section{Introduction}

A retrospective case series study analysis of head trauma patients presenting to the 48 Medical Model Compound Hospital between January and March 2017 were done. All patients requiring a CT head on admission and then a repeat (control) CT at 6 hours or more were included. The decision to perform
CT head was, according to admitting neurosurgical doctors' discretion. Also, their GCS was assessed twice before undergoing the control brain CT scans; once they arrived at the hospital, and then followed by another assessment after 3 hours. All patients with head trauma above 18 years of age who were admitted to the neurosurgery department and subjected to two or more CT 


\section{Open Access Journal of Neurology \& Neurosurgery}

scans of the brain were enrolled in this study. The decision to repeat a CT scan was taken by the neurosurgeon (Figures 1\&2).

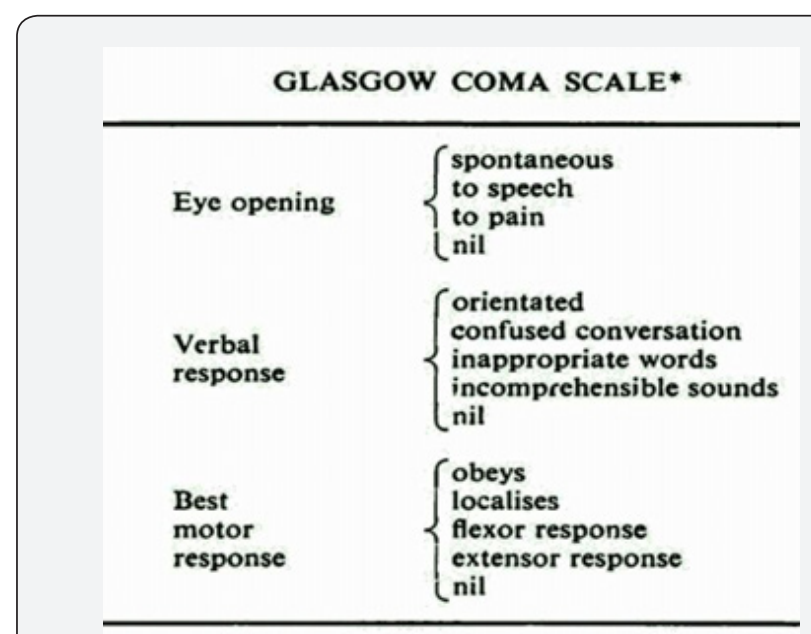

*Teasdale and Jennett (1974).

Figure 1: Glasgow Coma Scale (GCS).

\section{GLASGOW OUTCOME SCALE*}

\begin{tabular}{ll}
\hline Dead & - \\
$\begin{array}{l}\text { Persistent } \\
\text { vegetative }\end{array}$ & $\begin{array}{l}\text { Sleep/wake } \\
\text { non-sentient }\end{array}$ \\
$\begin{array}{l}\text { Severely } \\
\text { disabled }\end{array}$ & $\begin{array}{l}\text { Conscious but } \\
\text { dependent }\end{array}$ \\
$\begin{array}{l}\text { Moderately } \\
\text { disabled }\end{array}$ & $\begin{array}{l}\text { Independent } \\
\text { but disabled } \\
\text { Good recovery }\end{array}$ \\
$\begin{array}{l}\text { May have mild } \\
\text { residual }\end{array}$ \\
\hline
\end{tabular}

\section{* Jennett and Bond (1975).}

Figure 2: Glasgow Outcome Scale. (GOS).

Exclusion Criteria. The following patients were excluded from the study:

a. Patients, who were not referred to a neurosurgeon,

b. Patients, who died before the CT scan,

c. Patients with associated life-threatening injuries to other systems or polytrauma,

d. Patients who were taken up to surgery based upon the findings of the first CT scan,

e. Patients who were discharged or who expired after the first CT scans,

f. Patients who had a repeat head CT due to non-trauma related incidental findings (brain tumors, cysts).

g. Patients who are under anticoagulation or antiplatelet medication Patients who are under 18yrs of age. Patients who have chronic medical illnesses. h. Patients who admitted to neurointensive care unit.

\section{Results}

The total number of head trauma patients presenting to our Centre was 63. A control brain CT scans (six hours or more from the time of presentation/injury) was available for 27 patients (24 had blunt and 3 had penetrating head trauma). These were analyzed. In patients with blunt trauma $(n=24)$, the majority ( $\mathrm{n}=12$ (44\%) had normal initial brain CT scan and normal subsequent control brain CT scans. In all patients, the initial GCS was $15 / 15$ except in one patient it was $13 / 15$, but it has improved to $15 / 15$. In $4(14 \%)$ patients had evidence of haemorrhage in initial brain CT scans; the control brain CT scans showed no changes in pathology or in the haemorrhagic size in 2 patients. However, in the other 2 patients, although it showed no new changes in pathology, there was a significant decrease in the haemorrhagic size. Nevertheless, regardless of these findings, the initial GCS (14-12 /15) in all Patients had improved to 15/15.

\begin{tabular}{|c|c|c|c|c|c|}
\hline $\begin{array}{c}\text { First CT } \\
\text { Results }\end{array}$ & $\begin{array}{c}\text { No } \\
\text { difference } \\
\text { in control } \\
\text { CTs }\end{array}$ & $\begin{array}{c}\text { A new lesion } \\
\text { or increase } \\
\text { of } \\
\text { pathology in } \\
\text { control CTs }\end{array}$ & $\begin{array}{c}\text { Decrease of } \\
\text { pathology } \\
\text { in } \\
\text { control CTs }\end{array}$ & Total & GOS \\
\hline Normal & 12 & 0 & 0 & 12 & 5 \\
\hline Hemorrhage & 2 & 0 & 2 & 4 & 5 \\
\hline Fracture & 4 & 0 & 0 & 4 & 5 \\
\hline $\begin{array}{c}\text { Fracture + } \\
\text { hemorrhage }\end{array}$ & 3 & 1 & 0 & 4 & 5 \\
\hline $\begin{array}{c}\text { penetrating } \\
\text { injury }\end{array}$ & 2 & 0 & 1 & 3 & 5 \\
\hline
\end{tabular}

Figure 3: General characteristics of patients with control cranial CTs.

\begin{tabular}{|c|c|c|c|c|c|}
\hline $\begin{array}{l}\text { First CT } \\
\text { Results }\end{array}$ & Initial GCS & $\begin{array}{l}\text { Control } \\
\text { CTs } \\
\text { Finding }\end{array}$ & $\begin{array}{c}2^{\text {nd }} \text { GCS } \\
\text { assessment }\end{array}$ & $\begin{array}{l}\text { Outcome } \\
\text { GOS }\end{array}$ & $\begin{array}{l}\text { Total of } \\
\text { cases }\end{array}$ \\
\hline Normal & 13 & Normal & 15 & 5 & 1 \\
\hline Hemorrhage & 12.14 & $\begin{array}{c}\text { No } \\
\text { difference in } \\
\text { control CT } \\
\text { to Decrease } \\
\text { of pathology } \\
\text { in } \\
\text { control CTs }\end{array}$ & 15 & 5 & 4 \\
\hline $\begin{array}{c}\text { penetrating } \\
\text { injury }\end{array}$ & 13 & $\begin{array}{l}\text { Decrease of } \\
\text { pathology in } \\
\text { control CTs }\end{array}$ & 15 & 5 & 1 \\
\hline
\end{tabular}

Figure 4: General characteristics of patients with GCS change.

In another $4(14 \%)$ patients of skull fracture with haemorrhage, the control brain CT scans showed increased haemorrhagic size in 1 patient (25\%) but showed no new changes in either pathology or haemorrhagic size in the 3 patients (75\%). Their GCS, interestingly, remained at 15 /15. Whereas, in $4(14 \%)$ patients with skull fracture, but with no Haemorrhage, no new changes in pathology were noticed in their control brain CT scans as well as their GCS remained at $15 / 15$. In patients with penetrating head trauma (3 patients), $2(66 \%)$ patients analyzed to have the same pathology in both initial and control CT Scans. Also, their GCS remained at 15/15. 


\section{Open Access Journal of Neurology \& Neurosurgery}

However, a significant decrease in pathology was observed in the control CT scans of the other patient (33\%) as well as showed GCS improvement from 13/15 to 15/15.

Over all, all patients had clinical improvement and good outcome depending on of GCS and Glasgow Outcome Scale respectively (Figures 3-5).

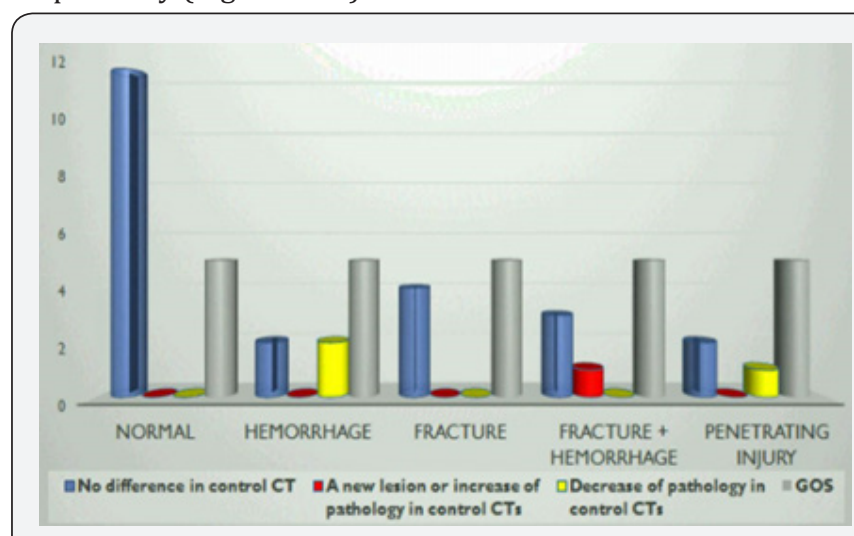

Figure 5: General characteristics of patients with control cranial CTs.

\section{Case Presentation}

\section{Presentation 1: -}

23-year-old male admitted with a blunt head trauma, the initial GCS was 15/15 and the 2nd assessment of GCS was 15/15. The initial brain CT showing a left occipital liner fracture with small epidural hematoma $(a, b)$. There was an increase of pathology in control brain CT (C) (Figure 6).
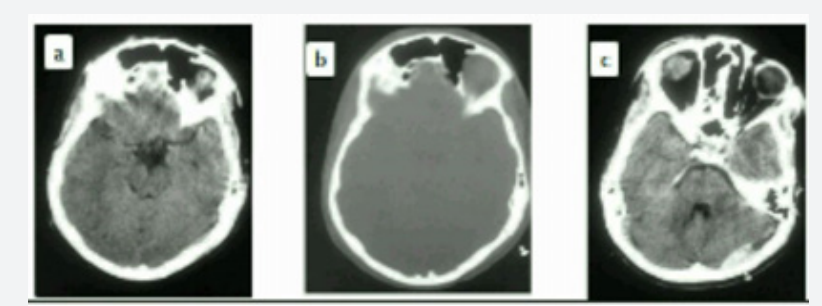

Figure 6: 23-year-old male admitted with a blunt head trauma, the initial GCS was $15 / 15$ and the 2 nd assessment of GCS was 15/15. The initial brain CT showing a left occipital liner fracture with small epidural hematoma $(a, b)$. There was an increase of pathology in control brain CT (c

\section{Case presentation 2: -}

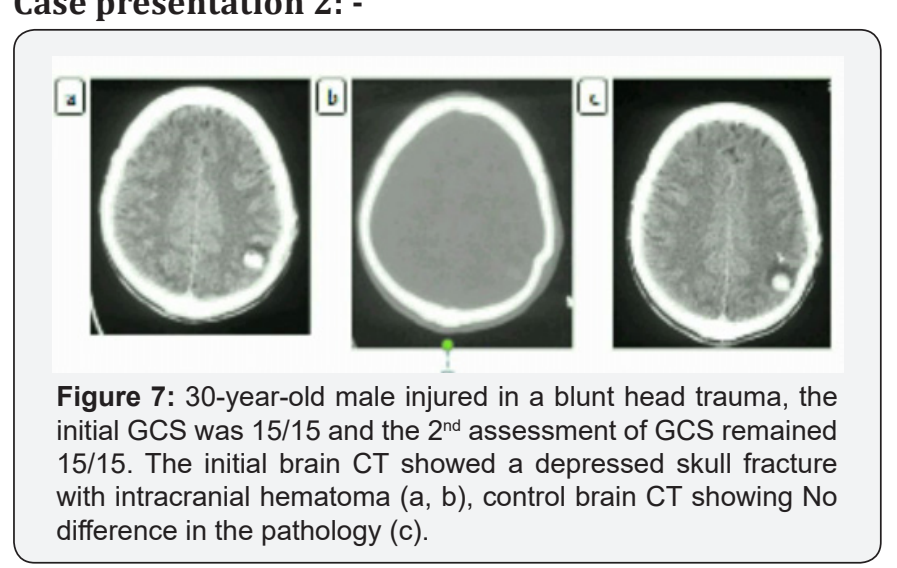

30-year-old male injured in a blunt head trauma, the initial GCS was 15/15 and the 2nd assessment of GCS remained 15/15. The initial brain CT showed a depressed skull fracture with intracranial hematoma (a, b), control brain CT showing No difference in the pathology (c) (Figure 7).

\section{Case presentation 3: -}

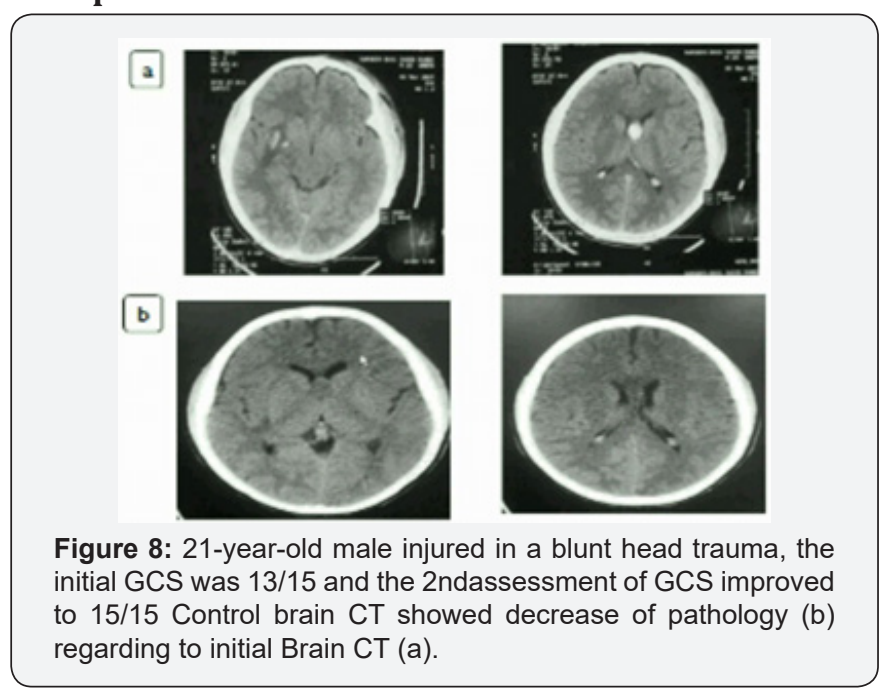

\section{Discussion}

Head Trauma is a common pathology seen in the Emergency Departments. And it is one of the most frequent and grave forms of neurologic disease. CT has been widely used for neuromonitoring of head trauma. CT is the gold standard for the detection of intracranial abnormalities and is a safe method for survey [12-14].

Guidelines of the immediate head CT scan and when a neurological deterioration occurs is Well-established [9]. However, there are no guidelines for the value of repeat CT scanning. Patients who present with head trauma often receives repeat CT scans to rule out the progression of their head injury. Controversy exists as to the role of a routine repeat head Computed Tomography (CT) for patients with traumatic brain injury and an initially abnormal head CT. Brown CV et al. reported that Patients with any head injury (mild, moderate, or severe) should undergo a repeat head CT after neurological deterioration, because it leads to intervention in over one-third of patients. Routine repeat head CT is indicated for patients with a GCS score $\leq 8$, as results might lead to intervention without neurological change [15-17].

Serkan Emre et al. study showed that the first CT scan of head trauma patients in EDs are good guides for the status of patients with mild head trauma patients. Repeated CT scans after 6 hours of observation in ED room were not necessary if first CT was normal in most situations [16]. Whereas, this result was consistent with results of this study.

Ramesh S Doddamani et al. [15] study showed that Repeat CT scans resulted in management changes even in patients with no clinical deterioration and thus may be of value in detecting 
changes at an early stage. Interventions based on the repeat CT are an important issue, because it may justify the cost of the study if that would improve the outcome for the patient [16]. But this study didn't show significance in the need for intervention in head trauma patients based on repeated CT if there were clinical deterioration.

concluded that Patients with a high Injury Severity Score (ISS) and/or those who are intubated have significantly higher odds of having a positive repeat head CT when repeated for follow-up or when clinically warranted [8]. This study has excluded critical head trauma patients and patients who admitted to neurointensive care unit and we will include them in further study. Similar study by Brown CV et al. reported that few patients with Traumatic Brain Injury (TBI) have their management altered after repeat head CT, and these patients had neurological deterioration before the repeat head CT [10]. Other study such as Chao A. study illustrated that patients with an unchanged or normal neurological exam, a routine serial $\mathrm{H}-\mathrm{CT}$ did not influence subsequent invasive neurosurgical intervention. Also, Dharap SB et al. study showed similar results. In this study we found no change in management in patients who not met the criteria of neurological intervention regarding of initial GCS and initial brain, if there is no clinical deterioration, the repeat CT scan is unlikely to reveal a lesion needing surgical intervention $[16,18,19]$.

Kessel Boris et al. is interesting study showed that Repeat CT of most head injured patients with GCS of 14-15, suffering from intracranial traumatic lesion, will not demonstrate significant changes in the size of intracranial hematoma. Increase in hematoma size is not prognostic factor of neurological deterioration. Routine repeat CT scan may not be justified in head trauma patients with GCS 14-15 on admission [20]. This study showed similar results but just one case presented with increased hematoma and no clinical deterioration or needed for neurosurgical intervention and it was not statistically significant. Ananda war SP et al. [13]. reported that a new "Neurologic Observation without Repeat HCT" (NORH) protocol with no repeat HCT scanning for patients admitted for MHI and ICH whose neurological status was maintained or improved to a Glasgow Coma Scale score of 15 at 24 hours after admission. The NORH protocol is safe and effective and can reduce radiation exposure and costs [13].

Serial brain CTs is a common practice to evaluate the progression of any pathological signs regardless of the clinical assessment in our country hospital. It increases the costs of hospitalization and crowding in EDs, increases resource use, exposes patients to unnecessary radiation. Some studies have demonstrated that no interventions were based on repeat CTs unless the patient had coagulopathy, hypotension, intracranial pressure elevation, or a marked neurologic deterioration and concluded that routine scheduled brain cranial CTs are unnecessary [16]. McCammaack Ck study repeated that head
CT in patients on anticoagulant and antiplatelet (ACAP) therapy that present after mild Traumatic Brain Injury (TBI) is not likely indicated in the absence of GCS deviation, Loc, neurosurgical deficit, clopidegrel, aspirin or compensation regimen use [21]. Serkan Emre Eroglu study demonstrated that patients with underlying chronic disease, patients who had fracture in first CTs, and patients who are taking antiplatelet agents. Need a special attention [16].

\section{Conclusion}

We concluded that the control brain CT scans after 6 hours or more from the event are not necessary in case the initial CT was normal or when there is no clinical deterioration regarding of GCS.

\section{Future work or limitation of this study}

a. Include all patients who admitted and all ages that well increase the sample size.

b. Include patients who admitted to neurointensive care unit.

c. Include all risky patient's groups (anticoagulation, antiplatelet or chronic medical illnesses)

d. Information and advice for patients who discharged

e. Follow up, for example, telephone review and monitoring to indicate which patients require inpatient rehabilitation.

f. Comparison of reporting accuracy of head CT scans by consultants (neuroradiologists, neurologists and emergency medicine).

\section{References}

1. Maas AI, Stocchetti N, Bullock R (2008) Moderate and severe traumatic brain injury in adults. Lancet Neurol 7(8): 728-741.

2. Alves ÓL, Bullock R (2001) Excitotoxic damage in traumatic brain injury. Brain Injury 1-36.

3. Mebrahtu-Ghebrehiwet, Quan M L, Andebirhan T (2009) The profile of CT scan findings in acute head trauma in Orotta Hospital, Asmara, Eritrea. Journal of the Eritrean Medical Association 4(1): 5-8.

4. Teasdale G, Jennett B (1974) Assessment of coma and impaired consciousness: a practical scale. Lancet 2(7872): 81-84.

5. Moore L, Lavoie A, Camden S, Le Sage N, Sampalis JS, et al. (2006) Statistical validation of the Glasgow coma score. J Trauma 60(6): 12381244.

6. Wade DT (1992) Measurement in neurological rehabilitation. Curr Opin Neurol Neurosurg 5(5): 682-686.

7. Brant WE, Helms CA (2012) Fundamentals of diagnostic radiology. In: Lippincott Williams \& Wilkins.

8. Muakkassa FF, Robert A Marley, Charudutt Paranjape, Elya Horattas BS, Ann Salvator, et al. (2012) Predictors of new findings on repeat head CT scan in blunt trauma patients with an initially negative head CT scan. Journal of the American College of Surgeons 214(6): 965-972.

9. Vos PE, Alekseenko Y, Battistin L, Ehler E, Gerstenbrand F, et al. (2012) Mild traumatic brain injury. Eur neur 19(2): 191-198. 


\section{Open Access Journal of Neurology \& Neurosurgery}

10. Brown CV, Weng J, Oh D, Salim A, Kasotakis G, et al. (2004) Does routine serial computed tomography of the head influence management of traumatic brain injury? A prospective evaluation. J Trauma 57(5): 939943

11. Jennett, B. and M. Bond, Assessment of outcome after severe brain damage: a practical scale. The Lancet 305(7905): 480-484.

12. Thomas BW, Mejia VA, Maxwell RA, Dart BW, Smith PW, et al. (2010) Scheduled repeat CT scanning for traumatic brain injury remains important in assessing head injury progression. J Am Coll Surg 210(5): 824-830.

13. Anandalwar SP, Mau CY, Gordhan CG, Majmundar N, Meleis A, et al. (2016) Eliminating unnecessary routine head CT scanning in neurologically intact mild traumatic brain injury patients: implementation and evaluation of a new protocol. J Neurosurg 125(3): 667-673.

14. Toyama Y, Kobayashi T, Nishiyama Y, Satoh K, Ohkawa M, et al. (2005) CT for acute stage of closed head injury. Radiat med 23(5): 309-316.

15. Doddamani RS, Sunil k guptha, Naveet singla, Sandeep Mohindra, Paramjeet singh, et al. (2012) Role of repeat CT scans in the management of traumatic brain injury. The indian journal of neurotrauma 9(1): 3339.

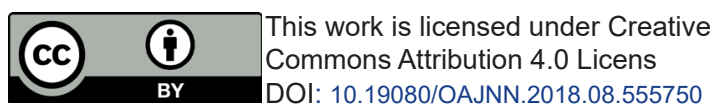

16. Eroglu SE, Ozge Onur, Sefere Ozkaya, Arzu Denizbasi, Hasan Demir, et al. (2013) Analysis of repeated CT scan need in blunt head trauma. Emergency medicine international 2013: 5.

17. Brown CV, Zada G, Salim A, Inaba K, Kasotakis G, et al. (2007) Indications for routine repeat head computed tomography (CT) stratified by severity of traumatic brain injury. J Trauma 62(6): 1339-1345.

18. Chao A, Pearl J, Perdue P, Wang D, Bridgeman A, et al. (2001) Utility of routine serial computed tomography for blunt intracranial injury. J Trauma 51(5): 870-876.

19. Dharap SB, Khandkar AA, Pandey A, Sharma AK (2005) Repeat CT scan in closed head injury. Injury 36(3): 412-416.

20. Kessel Boris, Itamar Ashkenazi, Zeina Abdel Rauf, Nachtigal Alicia, Korin Alexander et al. (2013) Is Routine Brain CT Scan, Performed for Early Follow Up in Head Trauma Patients with GCS 14-15, Always Justified. J Trauma Treat 2(174): 2167-1222.

21. McCammack KC, Sadler C, Guo Y, Ramaswamy RS, Farid N et al. (2015) Routine repeat head CT may not be indicated in patients on anticoagulant/antiplatelet therapy following mild traumatic brain injury. West J Emerg Med 16(1): 43-49.

Your next submission with Juniper Publishers
will reach you the below assets
- Quality Editorial service
- Swift Peer Review
- Reprints availability
- E-prints Service
- Manuscript Podcast for convenient understanding
- Global attainment for your research
- Manuscript accessibility in different formats
( Pdf, E-pub, Full Text, Audio)
- Unceasing customer service
Track the below URL for one-step submission
https://juniperpublishers.com/online-submission.php

